\title{
Single-base resolution of mouse offspring brain methylome reveals epigenome modifications caused by gestational folic acid
}

\author{
Subit Barua', Salomon Kuizon ${ }^{1}$, Kathryn K Chadman ${ }^{2}$, Michael J Flory ${ }^{3}$, W Ted Brown ${ }^{4}$ and Mohammed A Junaid ${ }^{1,5^{*}}$
}

\begin{abstract}
Background: Epigenetic modifications, such as cytosine methylation in $\mathrm{CpG}$-rich regions, regulate multiple functions in mammalian development. Maternal nutrients affecting one-carbon metabolism during gestation can exert long-term effects on the health of the progeny. Using C57BL/6 J mice, we investigated whether the amount of ingested maternal folic acid (FA) during gestation impacted DNA methylation in the offspring's cerebral hemispheres. Reduced representation bisulfite sequencing at single-base resolution was performed to analyze genome-wide DNA methylation profiles.

Results: We identified widespread differences in the methylation patterns of $\mathrm{CpG}$ and non- $\mathrm{CpG}$ sites of key developmental genes, including imprinted and candidate autism susceptibility genes $(P<0.05)$. Such differential methylation of the $\mathrm{CpG}$ and non-CpG sites may use different mechanisms to alter gene expressions. Quantitative real time reverse transcription-polymerase chain reaction confirmed altered expression of several genes.

Conclusions: These finding demonstrate that high maternal FA during gestation induces substantial alteration in methylation pattern and gene expression of several genes in the cerebral hemispheres of the offspring, and such changes may influence the overall development. Our findings provide a foundation for future studies to explore the influence of gestational FA on genetic/epigenetic susceptibility to altered development and disease in offspring.
\end{abstract}

\section{Background}

The folate cycle, in conjunction with one-carbon metabolism, facilitates nucleic acid synthesis and is responsible for the transfer of 1-carbon methyl groups to DNA and proteins. Methyl groups added onto cytosine residues in promoter region CpGs in genomic DNA are central to the regulation of gene expression [1,2]. The role of folic acid (FA) in preventing neurodevelopmental disorders and birth defects has long been recognized, and as such, its use during pregnancy is strongly emphasized [3-5]. Dietary FA supplementation is credited with a greater than $70 \%$ reduction in the incidence of neural tube defects (NTDs) in the US [6]. There has been speculation that FA

\footnotetext{
* Correspondence: mohammed.junaid@opwdd.ny.gov

${ }^{1}$ Department of Developmental Biochemistry, New York State Institute for Basic Research in Developmental Disabilities, 1050 Forest Hill Road, Staten Island, NY 10314, USA

${ }^{5}$ Structural Neurobiology Laboratory, Department of Developmental Biochemistry, New York State Institute for Basic Research in Developmental Disabilities, 1050 Forest Hill Road, Staten Island, NY 10314, USA Full list of author information is available at the end of the article
}

supplementation may be associated with certain aberrant conditions in children [7-9], and a clear understanding of this purported association is essential in view of the presence of significant amounts of synthetic FA in our diets. Earlier, we reported that exposure of lymphoblastoid cells to FA supplementation causes widespread changes in gene expression [10]. We suggested that the occurrence of such epigenetic changes during gestational development may impact the methylation status of DNA in the offspring's brain and cause altered gene expression. Because gestational development involves a highly orchestrated regulation of gene expression, such gene dysregulation may affect the development of the brain and may culminate in neuropsychiatric conditions. This could be a contributing factor to the increasing prevalence in recent years.

To test the hypothesis that excess FA supplementation could alter the methylation in the brains of offspring, 1 week prior to mating, a group of C57BL/6 J female mice were fed a custom AIN-93G amino acid-based diet (Research Diet, Inc., New Brunswick, NJ, USA), with FA at

\section{Biomed Central}


$0.4 \mathrm{mg} / \mathrm{kg}$ (low maternal folic acid, or LMFA) or $4 \mathrm{mg} / \mathrm{kg}$ (high maternal folic acid, or HMFA). FA at the $4 \mathrm{mg} / \mathrm{kg}$ level is above the range currently included in mice chow, whereas the $0.4 \mathrm{mg} / \mathrm{kg}$ level of FA has been found to be necessary for a normal healthy litter size [11]. FA at the 4 $\mathrm{mg} / \mathrm{kg}$ level in mice roughly corresponds to the $4 \mathrm{mg} /$ day dose in humans, which is the level of FA supplementation ( $4 \mathrm{mg} /$ day) prescribed to women with a history of NTD pregnancy. We used an amino acid-based diet to precisely control the amount of FA in the diet. To understand the dynamics of DNA methylation, genomic DNA from the cerebral hemispheres of the offspring was isolated at postnatal day 1 segregated by gender, and high-resolution, single-base DNA methylation profiling was performed by using next-generation Illumina (Illumina Inc., San Diego, CA, USA) sequencing (details in the Methods section).

\section{Results}

\section{Global DNA methylation patterns of the offspring's} cerebral hemispheres from high maternal folic acid

The final DNA methylation map presented in this study represents the summary of three biological replicates $[12,13]$, with each mouse collected from an independent litter. On average, the sequence depths of unique CpG sites in our study were 4,647,138 (11 times) for male and 4,410,480 (14 times) for female DNA samples (Additional file 1: Table S1), and about $90 \%$ of the CpG islands were covered. To investigate the differentially methylated regions (DMRs), sequence alignment and Fisher's exact test or $t$ test were performed for each CpG site that had at least five reads covered. Results of global methylation comparison revealed that approximately $16 \%$ of the CpG sites were differentially methylated in both male and female pups from HMFA ( $n=43,010$ for male, $n=57,602$ for female). The majority of the $\mathrm{CpG}$ island-associated DMRs were either intergenic or in introns, whereas $18 \%$ to $19 \%$ were in exons, and approximately $7 \%$ were in promoter regions (Figure 1a, b). Several genes involved in neural functioning, brain development, and synaptic plasticity were differentially methylated $(P<0.05)$ in the CpG sites of the offspring from HMFA (Tables 1, 2, 3 and 4, Additional file 2: Table S2, Additional file 3: Table S3, Additional file 4: Table S5, and Additional file 5: Table S6). The results of high-resolution global DNA methylation profiling indicated that maternal FA induces significant changes in the overall methylation patterns in the brains of the offspring. The correlations of the distribution of methylation ratios in male and female pups for the corresponding sites in LMFA and HMFA are shown in Additional file 6: Figures S1-S6, and the distributions of the overlapped sites between LMFA and HMFA male with that of LMFA and HMFA female differential methylation sites $(P<0.05)$ are shown as a hexbin plot in Additional file 7: Figures S7-S9.

\section{Maternal folic acid alters DNA methylation status in the promoters at CpG Islands}

In this study, we found that HMFA throughout gestation resulted in hypermethylation $(P<0.01)$ at $\mathrm{CpG}$ sites of the promoter region of several genes, including $A d a$, Bag5, and Trap1 in male offspring (Table 1), leading to downregulation of the expression of Ada and Bag5 and no such alterations in expression level of Trap1 (Figure 2a). In female pups, HMFA also resulted in hypermethylation at CpG sites in the promoter region of the genes Dio3, Polg2, Rnf111, and Ube2s, including several other genes (Table 1). Quantitative real time reverse transcriptionpolymerase chain reaction (qRT-PCR) analysis revealed that the expression of Dio3 was significantly downregulated and that, in contrast, the expression of Polg2, Rnf111, and $U b e 2 s$ remained unchanged in female pups from HMFA compared with that of LMFA (Figure 2b). To further reveal the impact of maternal FA, we assessed whether HMFA resulting in hypomethylation in the promoter regions of $\mathrm{CpG}$ islands altered the expression levels of those genes as well. We tested the expression of several genes in male (Pcnxl3, Hmgb21l, and Ror2) and female (Mrps12, Ceacam2, and Mtap4) pups (Table 1, Figure 2c, d). In male pups from HMFA, the expressions of Ror 2 and Mrps 12 were significantly downregulated, and in female pups, the expression of Mtap4 was significantly upregulated in comparison with LMFA. Interestingly, although the methylation level of Mrps12 did not show any significant change in male pups from HMFA, the expression was significantly downregulated. In contrast, the expression of Mrps12 in female pups from HMFA showed no difference in expression level, although significant methylation changes were observed. However, the expression analysis of several other genes-Pcnxl3, Hmgb21l, Mtap4, and Ceacam2has shown no significant changes in both the genders from HMFA. The results of our findings suggest that maternal FA modulates the methylation pattern of the offspring genome, and considering the role of maternal nutrition in early neural development, such changes in methylation patterns in promoter CpG sites due to HMFA may have long-term influences on neuronal organization and ultimately on behavioral phenotypes.

\section{Maternal folic acid alters DNA methylation status in the promoters at non-CpG sites}

To extend our findings, we then analyzed whether gestational FA modulates the methylation pattern of non-CpG sites. In this study, we obtained $89 \%$ coverage in non-CpG sites (both $\mathrm{CHH}$ and $\mathrm{CHG}$ context, where $\mathrm{H}=\mathrm{A}, \mathrm{C}$, or $\mathrm{T}$ ). The overall distribution of methylation level in the nonCpG sites is shown in Additional file 8: Figures S10 and 11 . We identified approximately 1,000 differentially methylated (both hyper- and hypo-methylation) sites $(P<0.05)$ in both $\mathrm{CHH}$ and $\mathrm{CHG}$ contexts in the offspring 


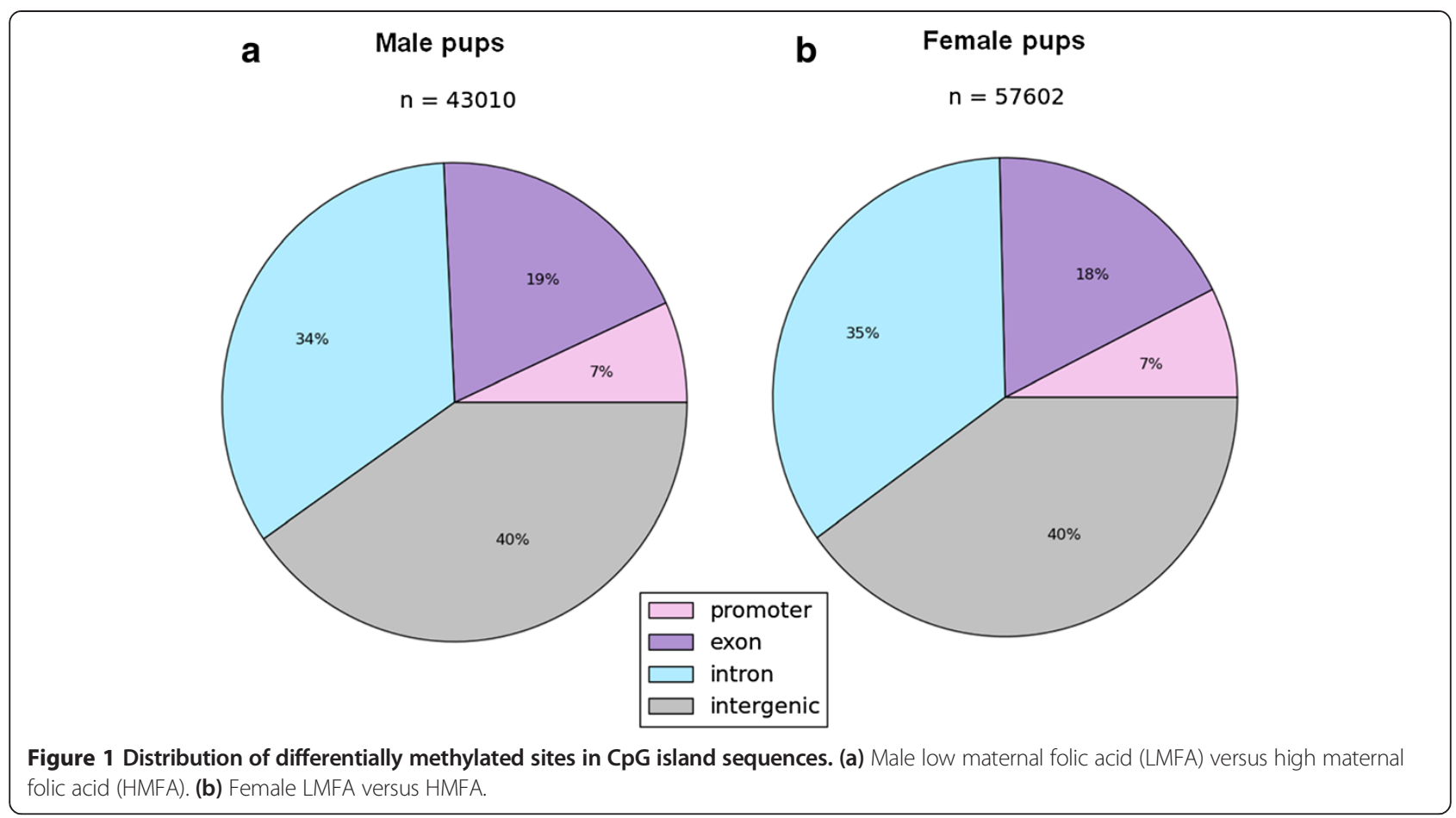

genome from the HMFA group (Additional file 2: Table S2, Additional file 3: Table S3, Additional file 9: Table S4, Additional file 4: Table S5, and Additional file 5: Table S6). For example, zinc finger proteins $Z f p 608$ and ephrin receptor Epha6 in male offspring and Zfp 719, Zfp804b, Zfp128 and calcium channel Cacna1g in female offspring are a few of the many genes that were hypermethylated $(P<0.05)$ in the non-CpG promoter sites (Additional file 9: Table S4). Furthermore, we tested expression levels of several genes (Ghr, Slc5a1, and 4732418C07Rik) in male pups and (Tshz3 and Trim7) in female pups with Quantitative real time reverse transcription-polymerase chain reaction (qRTPCR). The results showed that the expression of EF-hand calcium-binding domain 14 (4732418c07Rik) remain unchanged; in contrast, the expression of sodium-dependent glucose transporter (Slc5a1), which exhibited hypermethylation in CHG sites, and growth hormone receptor (Ghr) [14], which exhibited hypermethylation at both CHG and $\mathrm{CHH}$ sites in the promoter region, were downregulated in male offspring from HMFA (Figure 2a, Additional file 9: Table S4). A representative figure depicting the methylation status of a non-CpG (CHG) hypermethylation at Slc $5 a 1$ promoter of male offspring from the data uploaded in the UCSC Genome Browser is shown in Additional file 10: Figure S12.

\section{Maternal folic acid alters DNA methylation pattern in the gene body}

An interesting aspect of our data is the pattern of methylation in both $\mathrm{CpG}$ and non- $\mathrm{CpG}$ sites in gene bodies.
The majority of the non-CpG associated DMRs were either intergenic or in introns, whereas $10 \%$ to $11 \%$ were in exons, and approximately $16 \%$ to $21 \%$ were in promoter regions in both male and female pups from HMFA (Figure 3a, b). The overall distribution of methylation level in exons is shown in Additional file 11: Figure S13 and S14. Several candidate autism susceptibility genes [15] were hypermethylated $(P<0.05)$ in the HMFA, including Shank3, Cacana1g, Gtf2i, Rapgef4, and Nbea in male offspring and Ext1, Ube3a, Erbb4, Grip1, Grm8, Reeln, Shank3, and Rbfox 1 in female offspring (Additional file 2: Table S2 and Additional file 3: Table S3). In contrast, several candidate autism susceptibility genes were also hypomethylated; for example, Disc1, which is known to play a pivotal role in cortical development, and $S c n 8 a$, which modulates membrane depolarization, were hypomethylated in the gene body in both male and female offspring $(P<0.05)$ in the HMFA group (Additional file 4: Table S5 and Additional file 5: Table S6). It is interesting to note that autism susceptibility candidate 2 (Auts2) gene exhibited both hyper- and hypo-methylation in the gene bodies of male and female pups from HMFA. Further analysis of methylation profile also revealed hypermethylation in imprinted genes in male (Slc22a3 and Ano1) and in female (Gab1, Calcr, Dio3, and Slc38a4) offspring $(P<0.05)$ (Additional file 2: Table S2 and Additional file 3: Table S3). On the other hand, imprinted genes Peg12 and Slc22a18 in female offspring and cadherin-associated protein Ctnna3 in both male and female offspring from the HMFA group were hypomethylated (Additional file 4: 
Table 1 List of hypermethylated CpG sites in the promoter of genes from high maternal folic acid diet

\begin{tabular}{|c|c|c|c|c|c|c|c|}
\hline Chromosome & Start & End & Gene & $\begin{array}{l}\text { Total CpG } \\
\text { LMFA }\end{array}$ & $\begin{array}{l}\text { Total CpG } \\
\text { HMFA }\end{array}$ & $\begin{array}{l}\text { Methylation } \\
\text { difference }\end{array}$ & $P$ value \\
\hline \multicolumn{8}{|l|}{ Male-CpG } \\
\hline Chr1 & 174430052 & 174430053 & Tagln2 & 12 & 5 & -0.80 & 0.00 \\
\hline Chr2 & 124976701 & 124976702 & Slc12ar & 9 & 10 & -0.79 & 0.00 \\
\hline Chr2 & 163576501 & 163576502 & Ada & 7 & 5 & -0.80 & 0.01 \\
\hline Chr5 & 110658438 & 110658439 & Ankle2 & 10 & 6 & -0.80 & 0.01 \\
\hline $\mathrm{Chr} 7^{\mathrm{a}}$ & 25654980 & 25654981 & Dmrtc2 & 5 & 5 & -1.00 & 0.01 \\
\hline $\mathrm{Chr} 12^{\mathrm{a}}$ & 112951515 & 112951516 & Bag5 & 20 & 5 & -0.80 & 0.00 \\
\hline Chr13 & 21533599 & 21533600 & Pgbd1 & 11 & 5 & -0.91 & 0.00 \\
\hline Chr14 & 12384528 & 12384529 & Ptprg & 15 & 6 & -0.87 & 0.00 \\
\hline Chr16 & 4078495 & 4078496 & Trap1 & 17 & 20 & -0.85 & 0.00 \\
\hline Chr $18^{\mathrm{a}}$ & 25327450 & 25327451 & AW554918 & 11 & 10 & -0.80 & 0.00 \\
\hline Chr18 & 55150289 & 55150290 & Zfp608 & 8 & 5 & -0.80 & 0.01 \\
\hline ChrX & 70963189 & 70963190 & Bcap31 & 15 & 7 & -0.80 & 0.00 \\
\hline \multicolumn{8}{|l|}{ Female-CpG } \\
\hline Chr1 & 158239364 & 158239365 & Nphs2 & 5 & 5 & -0.80 & 0.05 \\
\hline Chr2 & 30141110 & 30141111 & Nup188 & 10 & 9 & -0.78 & 0.00 \\
\hline Chr2 & 93663150 & 93663151 & Ext2 & 7 & 9 & -0.78 & 0.00 \\
\hline Chr4 & 115456244 & 115456245 & Atpaf1 & 10 & 5 & -0.80 & 0.01 \\
\hline Chr7 & 4765788 & 4765789 & Ube2s & 12 & 14 & -0.79 & 0.00 \\
\hline Chr7 & 116076508 & 116076509 & Eif3f & 8 & 10 & -0.80 & 0.00 \\
\hline Chr9 & 43921237 & 43921238 & $R n f 26$ & 10 & 6 & -0.80 & 0.01 \\
\hline Chr9 & 43921243 & 43921244 & $R n f 26$ & 10 & 6 & -0.80 & 0.01 \\
\hline Chr9 & 70352700 & 70352701 & Rnf111 & 7 & 6 & -1.00 & 0.00 \\
\hline $\mathrm{Chr} 11^{\mathrm{a}}$ & 106640875 & 106640876 & Polg2 & 8 & 8 & -0.75 & 0.01 \\
\hline Chr12 & 111517321 & 111517322 & Dio3 & 8 & 8 & -0.75 & 0.01 \\
\hline Chr13 & 3147545 & 3147546 & Speer6-ps1 & 6 & 5 & -0.80 & 0.02 \\
\hline Chr13 & 38751553 & 38751554 & Eeflel & 10 & 6 & -0.80 & 0.01 \\
\hline Chr16 & 18624289 & 18624290 & Gp1bb & 8 & 5 & -0.75 & 0.02 \\
\hline Chr17 & 24806277 & 24806278 & Zfp598 & 7 & 6 & -0.86 & 0.00 \\
\hline $\mathrm{Chr} 18^{\mathrm{a}}$ & 51277441 & 51277442 & Prri6 & 7 & 5 & -0.80 & 0.01 \\
\hline Chr18 & 60932782 & 60932783 & Rps14 & 5 & 9 & -0.78 & 0.02 \\
\hline ChrX & 7721523 & 7721524 & 2900002K06Rik & 6 & 13 & -0.76 & 0.00 \\
\hline ChrX & 155852426 & 155852427 & Mtap7d2 & 14 & 17 & -0.82 & 0.00 \\
\hline
\end{tabular}

${ }^{a}$ Methylation exclusively in the CpG island of promoter region. HMFA, high maternal folic acid; LMFA, low maternal folic acid.

Table S5 and Additional file 5: Table S6). To verify changes in the expression levels, we tested the mRNA expression of several genes by qRT-PCR. Genes in male pups (Auts2, Mthfd1l, Mtnr1b, Nfix, Otoa, Runx1, Shank3, Slc22a3, and Wif1) and in female pups (Auts2, Gab1, Lats2, Runx1, Wif1, Mthfd1, Shank3, and Slc25a13) were analyzed. The results revealed that the expressions of Auts2, Nfix, Otoa, Runx1, Shank3, and Slc22a3 were significantly downregulated; in contrast, the expression of Mthfd1l, Mtnr1b, and Wif1 did not exhibit significant changes as a result of
HMFA in comparison with LMFA in male pups (Figure 2a). In female pups from the HMFA group, the expression of Auts2, Gab1, Lats2, Runx1, Wif1, and Mthfd1 did not exhibit significant changes; in contrast, the expressions of Shank3 and Slc25a13 were significantly downregulated (Figure 2b). We further analyzed the expression of several genes which exhibited hypomethyaltion in the gene body of several genes (Cd47, Disc1, Dnm3, Evl, Sn8a, and Homer2) in both male and female pups from HMFA in comparison with LMFA (Figure 2c, d). The result of gene 
Table 2 List of hypomethylated CpG sites in the promoter of genes from high maternal folic acid diet

\begin{tabular}{|c|c|c|c|c|c|c|c|}
\hline Chromosome & Start & End & Gene & $\begin{array}{l}\text { Total CpG } \\
\text { LMFA }\end{array}$ & $\begin{array}{l}\text { Total CpG } \\
\text { HMFA }\end{array}$ & $\begin{array}{l}\text { Methylation } \\
\text { difference }\end{array}$ & $P$ value \\
\hline \multicolumn{8}{|l|}{ Male-CpG } \\
\hline Chr2 & 104335383 & 104335384 & Hipk3 & 6 & 10 & -0.80 & 0.01 \\
\hline Chr2 & 118590048 & 118590049 & A430105/19Rik & 6 & 7 & -0.83 & 0.00 \\
\hline Chr2 & 164156736 & 164156737 & Svs 5 & 5 & 6 & -0.83 & 0.02 \\
\hline Chr2 & 171789984 & 171789985 & 1700028P15Rik & 17 & 5 & -0.80 & 0.00 \\
\hline Chr4 & 135283630 & 135283631 & 1122ral & 5 & 5 & -0.80 & 0.05 \\
\hline Chr5 & 122070856 & 122070857 & Acad12 & 6 & 11 & -0.73 & 0.01 \\
\hline Chr7 & 3219409 & 3219410 & Mir291b & 8 & 11 & -0.75 & 0.00 \\
\hline Chr7 & 7253725 & 7253726 & Clcn4-2 & 6 & 9 & -0.72 & 0.01 \\
\hline $\mathrm{Chr}^{\mathrm{a}}$ & 15208940 & 15208941 & Gm18756 & 10 & 12 & -0.83 & 0.00 \\
\hline Chr7 & 91836603 & 91836604 & 2610206C17Rik & 6 & 5 & -0.83 & 0.02 \\
\hline Chr8 & 34495178 & 34495179 & Purg & 5 & 5 & -0.80 & 0.05 \\
\hline Chr8 & 73034757 & 73034758 & Uba52 & 6 & 6 & -0.83 & 0.02 \\
\hline Chr8 & 77516944 & 77516945 & Hmgxb4 & 6 & 15 & -0.77 & 0.00 \\
\hline Chr9 & 66892554 & 66892555 & Tpm1 & 15 & 6 & -0.73 & 0.00 \\
\hline Chr10 & 53239171 & 53239172 & Gm20597 & 8 & 7 & -0.75 & 0.01 \\
\hline Chr12 & 3235150 & 3235151 & $1700012 B 15 R i k$ & 16 & 18 & -0.88 & 0.00 \\
\hline Chr13 & 53382125 & 53382126 & Ror2 & 6 & 5 & -0.80 & 0.02 \\
\hline Chr13 & 53382128 & 53382129 & Ror2 & 6 & 5 & -1.00 & 0.00 \\
\hline Chr13 & 97839933 & 97839934 & Fam169a & 5 & 8 & -0.75 & 0.02 \\
\hline Chr13 & 100671338 & 100671339 & Cartpt & 5 & 5 & -0.80 & 0.05 \\
\hline Chr14 & 67628989 & 67628990 & Bnip3l & 7 & 8 & -0.75 & 0.01 \\
\hline Chr19 & 5690281 & 5690282 & Pcnx/3 & 20 & 13 & -0.80 & 0.00 \\
\hline \multicolumn{8}{|l|}{ Female-CpG } \\
\hline Chr2 & 127618583 & 127618584 & 1500011 K16Rik & 11 & 20 & -0.85 & 0.00 \\
\hline $\mathrm{Chr}^{\mathrm{a}}$ & 100468191 & 100468192 & Enoph1 & 11 & 5 & -0.71 & 0.01 \\
\hline $\mathrm{Chr}^{\mathrm{a}}$ & 52196197 & 52196198 & Hoxa11 & 5 & 5 & -0.80 & 0.05 \\
\hline Chr6 & 100476908 & 100476909 & 1700049E22Rik & 10 & 5 & -0.80 & 0.00 \\
\hline Chr7 & 26326796 & 26326797 & Ceacam2 & 6 & 15 & -0.77 & 0.00 \\
\hline Chr7 & 29528469 & 29528470 & Mrps12 & 16 & 5 & -0.80 & 0.00 \\
\hline Chr7 & 86988105 & 86988106 & Anpep & 12 & 5 & -0.83 & 0.00 \\
\hline Chr8 & 87469964 & 87469965 & Rtbdn & 7 & 6 & -0.86 & 0.00 \\
\hline Chr8 & 116657191 & 116657192 & Nudt7 & 14 & 5 & -0.71 & 0.01 \\
\hline Chr9 & 109833746 & 109833747 & Mtap4 & 8 & 14 & -0.71 & 0.00 \\
\hline Chr10 & 76992742 & 76992743 & $\operatorname{ltg} b 2$ & 8 & 7 & -0.71 & 0.01 \\
\hline Chr10 & 80846466 & 80846467 & Dohh & 8 & 13 & -0.69 & 0.00 \\
\hline Chr11 & 88727116 & 88727117 & Akap 1 & 6 & 5 & -0.80 & 0.02 \\
\hline Chr11 & 115184397 & 115184398 & Ushig & 12 & 5 & -0.75 & 0.01 \\
\hline Chr11 & 118204319 & 118204320 & $B C 100451$ & 20 & 7 & -0.81 & 0.00 \\
\hline Chr11 & 119909421 & 119909422 & Aatk & 7 & 5 & -0.71 & 0.03 \\
\hline Chr11 & 120051942 & 120051943 & 2810410L24Rik & 10 & 5 & -0.70 & 0.02 \\
\hline Chr12 & 52447904 & 52447905 & G2e3 & 8 & 5 & -0.75 & 0.02 \\
\hline $\mathrm{Chr} 14^{\mathrm{a}}$ & 63380523 & 63380524 & Ints6 & 5 & 6 & -0.80 & 0.02 \\
\hline
\end{tabular}


Table 2 List of hypomethylated CpG sites in the promoter of genes from high maternal folic acid diet (Continued)

\begin{tabular}{llllllll}
\hline Chr15 & 81561248 & 81561249 & Rangap1 & 13 & 5 & -0.72 & 0.01 \\
Chr17 & 52020946 & 52020947 & Gm20098 & 9 & 7 & -0.71 & 0.00 \\
Chr18 & 38762241 & 38762242 & Spry4 & 6 & 5 & -0.83 & 0.02 \\
Chr18 & 60933042 & 60933043 & Rps14 & 9 & 8 & -0.76 & 0.00 \\
Chr19 & 7070128 & 7070129 & Trpt1 & 8 & 6 & -0.71 & 0.03
\end{tabular}

${ }^{a}$ Methylation exclusively in the CpG island of promoter region. HMFA, high maternal folic acid; LMFA, low maternal folic acid.

expression in male pups revealed significant downregulation in the expression of Evl and Homer2 whereas no such significant differences in expression of Cd47, Disc1, Dnm3, and $S n 8 a$ were observed. In contrast, in female pups, the expression of $\mathrm{Sn} 8 \mathrm{a}$ was downregulated and the expressions of $C d 47$, Disc1, and $E v l$ were upregulated whereas the expression of Dnm3 did not exhibit any change in expression.

\section{Maternal folic acid modulates sex-specific alterations in global DNA methylation in the offspring's cerebral hemispheres}

We further investigated the impact of maternal FA during gestation on epigenetic alterations throughout the genome in a sex-specific manner. Comparison between male and female pups' cerebral hemispheres from mothers fed an LMFA or HMFA revealed significant sexual dimorphism for global DNA methylation. Approximately 21\% of the CpG sites were differentially methylated between males and females from both LMFA $(\mathrm{n}=55,640)$ and HMFA $(\mathrm{n}=45,634)$. The distributions of CpG-island and nonCpG island associated methylations between male and female are shown in Additional file 12: Figure S15 and Additional file 13: Figure S16a,b. The majority of the DMRs in CpG or non-CpG island between males and females from LMFA and HMFA were in intergenic or in introns, whereas $9 \%$ to $20 \%$ in exons and $10 \%$ to $21 \%$ were in promoter regions. Further analysis of the data revealed striking sexual dimorphism in methylation patterns of numerous genes as a result of both LMFA and HMFA (Additional file 14: Table S7, Additional file 15: Table S8, Additional file 16: Table S9, and Additional file 17: Table S10). The correlation of the distribution of methylation ratios between male and female pups for the corresponding sites in LMFA and HMFA is shown in Additional file 18: Figure S17a,b,c and Additional file 19: Figure S18a,b,c, and the hexbin plot (Additional file 20: Figure S19a,b,c) shows the distribution of the overlapped sites between genders of LMFA and HMFA from total significant $(P<0.05)$ differential methylation sites. To evaluate whether the expressions of the tested genes in this study were biased by gender, we analyzed the expression of several genes between male and female pups from LMFA and HMFA, which exhibited changes in methylation profile. First we compared the expression of genes Trap1, Runx1,
Scn $8 a$, and Cd47 (hypermethylated) and Auts2 and Rnf111 (hypomethylated) in female pups from LMFA in comparison with LMFA from male pups (Additional file 21: Figure S20a). The results show that the expressions of Trap1 and $C d 47$ were significantly downregulated and the expression of Runx1 was upregulated, whereas the expressions of Scn8a, Auts2, and Rnf111 remained unchanged. Similarly, we compared the expression of genes Dio3, Trim7, Shank3, Slc25a13, Auts2, Disc1, and Dnm3 (hypermethylated) and Bag5, Ghr, Ror2, and Runx1 (hypomethylated) in female pups from HMFA in comparison with HMFA from male pups (Additional file 21: Figure S20b). The results show that the expressions of Dio3, Trim7, Shank3, Slc25a13, Auts2, Disc1, Ror2, and Runx1 were upregulated, whereas the expressions of Bag5 and Ghr were downregulated and the expression of Dnm3 remained unchanged. These results show that expressions of several genes are biased between male and female pups both in the basal level (LMFA) and as a result of HMFA.

Moreover, to control and maintain the sexual-dimor phism hypothesis, we further analyzed the expression of several tested genes, which exhibited sexual dimorphism in methylation profile. For example, genes which exhibited changes in methylation level in male pups as a results of HMFA are tested in female pups (no changes in methylation profile); similarly, genes which exhibited changes in methylation level in female pups as a result of HMFA are tested in male pups (no change in methylation profile). The expression analysis of genes Dio3, Polg2, Rnf111, Ube2s, Thsz3, Trim7, Gab1, Lats2, and Slc25a13 (hypermethylated, in female pups) and Mrps12, Mtap4, and Ceacam2 (hypomethylated in female pups) were tested in male pups from HMFA in comparison with male pups from LMFA (Additional file 22: Figure S21a). The expression of Rnf111 was upregulated and the expression of Mrps12 (Figure 2c) was downregulated, whereas other tested genes did not exhibit any significant changes in male pups. It is interesting to note that the expressions of Dio3 and Slc25a13 were significantly downregulated and the expressions of Thsz3 and Mtap4 were significantly upregulated in female pups from HMFA in comparison with LMFA (Figure 2b, d). Similarly, we tested the expression of several genes in female pups from HMFA which exhibited no changes in methylation compared with female pups from LMFA. For example, the 
Table 3 List of top 20 hypermethylated CpG sites in the gene body of genes from high maternal folic acid diet

\begin{tabular}{|c|c|c|c|c|c|c|c|}
\hline Chromosome & Start & End & Gene & $\begin{array}{l}\text { Total CpG } \\
\text { LMFA }\end{array}$ & $\begin{array}{l}\text { Total CpG } \\
\text { HMFA }\end{array}$ & $\begin{array}{l}\text { Methylation } \\
\text { difference }\end{array}$ & $P$ value \\
\hline \multicolumn{8}{|l|}{ Male } \\
\hline Chr3 & 138455425 & 138455426 & Tspan5 & 15 & 20 & 0.90 & 0.00 \\
\hline Chr4 & 119140980 & 119140981 & Rimkla & 21 & 15 & 0.79 & 0.00 \\
\hline Chr4 & 119140989 & 119140990 & Rimkla & 37 & 16 & 0.77 & 0.00 \\
\hline Chr4 & 119141016 & 119141017 & Rimkla & 21 & 15 & 0.79 & 0.00 \\
\hline Chr4 & 119610724 & 119610725 & Hivep3 & 11 & 9 & 0.89 & 0.00 \\
\hline Chr8 & 87012542 & 87012543 & Cacnala & 8 & 12 & 0.88 & 0.00 \\
\hline Chr8 & 94181294 & 94181295 & Fto & 28 & 22 & 0.79 & 0.00 \\
\hline Chr9 & 15678801 & 15678802 & Mtnrib & 7 & 10 & 1.00 & 0.00 \\
\hline Chr9 & 106735686 & 106735687 & Vprbp & 12 & 12 & 1.00 & 0.00 \\
\hline Chr9 & 106735687 & 106735688 & Vprbp & 20 & 10 & 0.90 & 0.00 \\
\hline Chr9 & 110562402 & 110562403 & Ccdc12 & 14 & 22 & 0.86 & 0.00 \\
\hline Chr10 & 115535492 & 115535493 & Ptprr & 14 & 9 & 0.86 & 0.00 \\
\hline Chr13 & 84421455 & 84421456 & Tmem161b & 8 & 12 & 0.88 & 0.00 \\
\hline Chr13 & 93030034 & 93030035 & Msh3 & 363 & 63 & 0.83 & 0.00 \\
\hline Chr14 & 75232739 & 75232740 & Lrch1 & 18 & 10 & 0.89 & 0.00 \\
\hline Chr15 & 89378341 & 89378342 & Shank3 & 17 & 9 & 0.83 & 0.00 \\
\hline Chr18 & 37951652 & 37951653 & Pcdha4-g & 14 & 10 & 1.00 & 0.00 \\
\hline Chr18 & 60852504 & 60852505 & Ndst 1 & 12 & 6 & 1.00 & 0.00 \\
\hline Chr18 & 65119073 & 65119074 & Nedd4l & 18 & 17 & 0.89 & 0.00 \\
\hline Chr19 & 31290367 & 31290368 & Prkgl & 17 & 16 & 0.76 & 0.00 \\
\hline \multicolumn{8}{|l|}{ Female } \\
\hline Chr2 & 25434932 & 25434933 & Gm996 & 9 & 13 & 0.85 & 0.00 \\
\hline Chr3 & 30935498 & 30935499 & Prkci & 10 & 8 & 1.00 & 0.00 \\
\hline Chr3 & 103739555 & 103739556 & Rsbn1 & 9 & 15 & 0.89 & 0.00 \\
\hline Chr4 & 126102080 & 126102081 & Eif2c3 & 19 & 17 & 0.74 & 0.00 \\
\hline Chr4 & 140978449 & 140978450 & Hspb7 & 6 & 19 & 0.83 & 0.00 \\
\hline Chr4 & 150546918 & 150546919 & Camtal & 22 & 6 & 0.83 & 0.00 \\
\hline Chr5 & 65200088 & 65200089 & KIf3 & 47 & 36 & 0.72 & 0.00 \\
\hline Chr5 & 103970283 & 103970284 & Ptpn13 & 23 & 12 & 0.74 & 0.00 \\
\hline Chr5 & 131698838 & 131698839 & Wbscr17 & 21 & 16 & 0.73 & 0.00 \\
\hline Chr7 & 53799845 & 53799846 & Sergef & 14 & 21 & 0.71 & 0.00 \\
\hline Chr8 & 35200739 & 35200740 & Leprot/1 & 25 & 10 & 0.76 & 0.00 \\
\hline Chr9 & 8001572 & 8001573 & Yap1 & 11 & 15 & 0.73 & 0.00 \\
\hline Chr9 & 42341123 & 42341124 & Grik4 & 39 & 30 & 0.73 & 0.00 \\
\hline Chr10 & 88898375 & 88898376 & Gas 213 & 14 & 11 & 0.82 & 0.00 \\
\hline Chr11 & 3211676 & 3211677 & Gm11944 & 10 & 35 & 0.74 & 0.00 \\
\hline Chr11 & 115670841 & 115670842 & Caskin2 & 8 & 14 & 0.86 & 0.00 \\
\hline Chr14 & 58310412 & 58310413 & Lats2 & 6 & 24 & 1.00 & 0.00 \\
\hline Chr16 & 34322324 & 34322325 & Kalrn & 12 & 14 & 0.71 & 0.00 \\
\hline Chr17 & 86912790 & 86912791 & Prkce & 8 & 18 & 0.89 & 0.00 \\
\hline Chr19 & 25161873 & 25161874 & Dock8 & 16 & 12 & 0.75 & 0.00 \\
\hline
\end{tabular}

HMFA, high maternal folic acid; LMFA, low maternal folic acid. 
Table 4 List of top 20 hypomethylated CpG sites in the genebody of genes from high maternal folic acid diet

\begin{tabular}{|c|c|c|c|c|c|c|c|}
\hline Chromosome & Start & End & Gene & $\begin{array}{l}\text { Total CpG } \\
\text { LMFA }\end{array}$ & $\begin{array}{l}\text { Total CpG } \\
\text { HMFA }\end{array}$ & $\begin{array}{l}\text { Methylation } \\
\text { difference }\end{array}$ & $P$ value \\
\hline \multicolumn{8}{|l|}{ Male } \\
\hline Chr1 & 182625573 & 182625574 & Mixl1 & 28 & 10 & -0.76 & 0.00 \\
\hline Chr2 & 25376181 & 25376182 & Traf2 & 24 & 14 & -0.77 & 0.00 \\
\hline Chr3 & 37380649 & 37380650 & Spata5 & 14 & 18 & -0.78 & 0.00 \\
\hline Chr5 & 145038432 & 145038433 & Baiap2/1 & 58 & 20 & -0.87 & 0.00 \\
\hline Chr5 & 145038431 & 145038432 & Baiap2/1 & 28 & 20 & -0.73 & 0.00 \\
\hline Chr6 & 63336567 & 63336568 & Grid2 & 12 & 11 & -0.83 & 0.00 \\
\hline Chr8 & 119917212 & 119917213 & Cmip & 12 & 10 & -0.80 & 0.00 \\
\hline Chr9 & 49203682 & 49203683 & Drd2 & 14 & 7 & -0.93 & 0.00 \\
\hline Chr10 & 86298137 & 86298138 & $N+5 d c 3$ & 20 & 6 & -0.83 & 0.00 \\
\hline Chr11 & 89264853 & 89264854 & 4932411E22Rik & 12 & 8 & -1.00 & 0.00 \\
\hline Chr11 & 88387073 & 88387074 & Msi2 & 11 & 10 & -0.90 & 0.00 \\
\hline Chr12 & 73229241 & 73229242 & Ccdc175 & 19 & 6 & -0.83 & 0.00 \\
\hline Chr13 & 117804995 & 117804996 & Parp8 & 12 & 6 & -1.00 & 0.00 \\
\hline Chr16 & 49910445 & 49910446 & $\mathrm{Cd} 47$ & 8 & 10 & -1.00 & 0.00 \\
\hline Chr16 & 96296259 & 96296260 & Brwd1 & 24 & 8 & -0.83 & 0.00 \\
\hline Chr17 & 80761785 & 80761786 & Arhgef33 & 20 & 13 & -0.77 & 0.00 \\
\hline Chr17 & 64485735 & 64485736 & Fert2 & 9 & 14 & -0.82 & 0.00 \\
\hline Chr18 & 36751828 & 36751829 & Ankhd 1 & 20 & 10 & -0.90 & 0.00 \\
\hline Chr19 & 5690281 & 5690282 & Map3k11 & 20 & 13 & -0.80 & 0.00 \\
\hline ChrX & 98171409 & 98171410 & Tex11 & 10 & 6 & -1.00 & 0.00 \\
\hline \multicolumn{8}{|l|}{ Female } \\
\hline $\mathrm{Chr}^{\mathrm{a}}$ & 106890569 & 106890570 & Cdh2O & 15 & 14 & -0.73 & 0.00 \\
\hline Chr3 & 53010469 & 53010470 & Lhfp & 12 & 10 & -0.92 & 0.00 \\
\hline Chr4 & 137849617 & 137849618 & Kif17 & 9 & 14 & -0.86 & 0.00 \\
\hline Chr4 & 142704605 & 142704606 & Prdm2 & 15 & 11 & -0.73 & 0.00 \\
\hline Chr4 & 21913536 & 21913537 & 6230409E13Rik & 23 & 10 & -0.71 & 0.00 \\
\hline Chr4 & 46546442 & 46546443 & Trim14 & 16 & 11 & -0.75 & 0.00 \\
\hline Chr4 & 117003265 & 117003266 & Rnf220 & 16 & 6 & -0.83 & 0.00 \\
\hline Chr5 & 148775977 & 148775978 & Mtus2 & 20 & 14 & -0.76 & 0.00 \\
\hline Chr5 & 37274842 & 37274843 & Ppp2r2C & 14 & 17 & -0.75 & 0.00 \\
\hline Chr8 & 121359642 & 121359643 & Cdh13 & 17 & 10 & -0.74 & 0.00 \\
\hline Chr9 & 21909321 & 21909322 & Cnn1 & 10 & 6 & -1.00 & 0.00 \\
\hline Chr9 & 44605440 & 44605441 & Tmem25 & 16 & 10 & -0.75 & 0.00 \\
\hline Chr11 & 96309521 & 96309522 & Gm11529 & 25 & 10 & -0.88 & 0.00 \\
\hline Chr11 & 118204319 & 118204320 & Timp2 & 20 & 7 & -0.81 & 0.00 \\
\hline Chr11 & 98634354 & 98634355 & Nrldl & 7 & 15 & -0.87 & 0.00 \\
\hline Chr15 & 99627500 & 99627501 & Lima1 & 25 & 22 & -0.74 & 0.00 \\
\hline Chr15 & 59208541 & 59208542 & Nsmce2 & 9 & 6 & -1.00 & 0.00 \\
\hline Chr16 & 49910445 & 49910446 & $\mathrm{Cd} 47$ & 10 & 12 & -0.83 & 0.00 \\
\hline Chr17 & 26016873 & 26016874 & Wfikkn1 & 36 & 20 & -0.73 & 0.00 \\
\hline Chr17 & 28437426 & 28437427 & Ppard & 8 & 22 & -0.83 & 0.00 \\
\hline
\end{tabular}

${ }^{a}$ Methylation exclusively in the CpG island. HMFA, high maternal folic acid; LMFA, low maternal folic acid. 

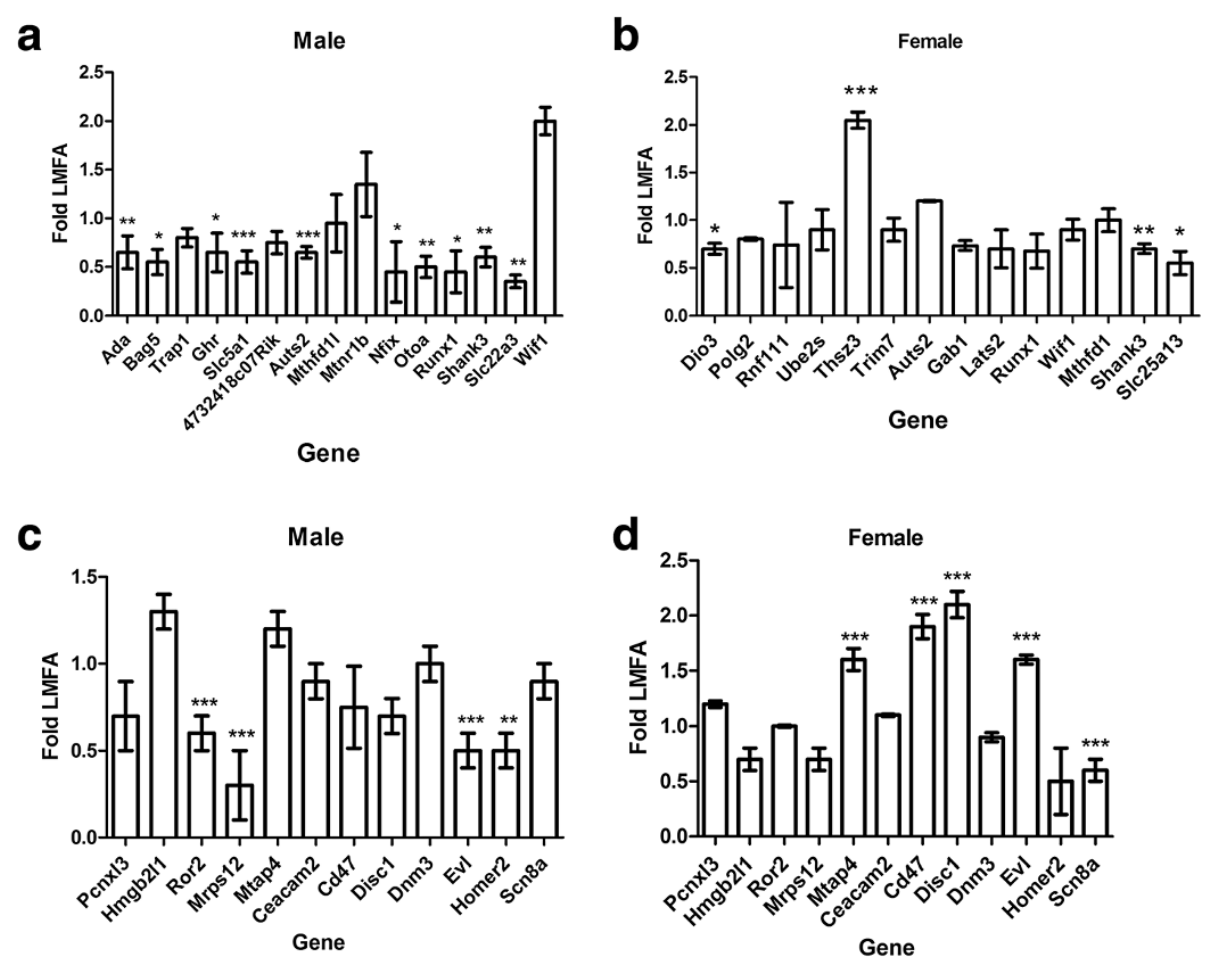

Figure 2 Relative expression of the genes that exhibited hypermethylation (a, b) and hypomethylation (c, d). The results were normalized to Hprt transcript expression and were expressed as relative values in comparison with corresponding transcripts from low maternal folic acid (LMFA). Results represent mean \pm standard deviation (SD); asterisks denote statistically significant change $\left.{ }^{*} P<0.05,{ }^{* *} P<0.01,{ }^{* * *} P<0.001\right)$.

expressions of genes Ada, Bag5, Trap1, Ghr, 4732418 C07Rik, Mthfd1l, Nfix, Otoa, and Slc22a3 (hypermethylated in male pups) and Pcnxl3, Hmgb2l1, and Ror2 (hypomethyalted, in male pups) were tested. The results showed (Additional file 22: Figure S21b) that the expression of $A d a, B a g 5$, and Slc22a3 were unchanged in female pups from HMFA in comparison with LMFA. In contrast, the expressions of Ghr and Nfix were upregulated in female pups from HMFA. It is interesting to note that the expression of Otoa is downregulated whereas the expressions of Trap1, 4732418C07Rik, Mthfd1l, Pcnxl3, Hmgb2l1, and Ror 2 remained unchanged in both male and female pups as results of HMFA. These results show that the expressions of several tested genes are sexually biased as a result of HMFA. Additionally, we have evaluated that the methylation patterns were affected in cis-alteration in $\mathrm{CpG}$ and CHG contexts in both males and females (Additional file 23: Table S11).

\section{Discussion}

In a fertilized egg, global DNA demethylation followed by remethylation occurs to reprogram the maternal and paternal genomes for efficient regulation of gene expression. Certain genes are turned on and off at particular time intervals, and any disruption of such highly orchestrated methylation regulation may impact gene expression.
The fetal epigenome is most vulnerable during this period of development to epigenetic modifiers in the maternal microenvironment. Because lifestyle and the level of nutrition available during gestation play an important role in the offsprings' gene regulation, maternal FA consumed could dictate the establishment of epigenetic patterns of the offspring. In this study, we found that HMFA during gestation resulted in substantial changes in the methylation profile of the offspring's cerebral hemispheres. Over the years, numerous studies have implicated several candidate autism susceptibility genes with a logical focus on the affected child. However, a consistent picture of specific susceptibility loci has thus far met with limited success [16-18]. In humans, FA during gestation has been shown to prevent autism or NTDs [19-21]. Intriguingly, our results showed hypermethylation but no hypomethylation in the promoter region of candidate autistic and imprinted genes in the offspring from the HMFA group. In this study, we found that HMFA resulted in hypermethylation $(P<0.01)$ at the CpG sites of the promoter region of $A d a$ in male offspring. It is noteworthy that previous evidence had suggested decreased Ada activity in autistic subjects [22-24] and in a severe combined immune deficiency syndrome $[25,26]$. Thus, such changes in methylation patterns in promoter CpG sites due to HMFA may have longterm influences on neuronal organization and behavioral 


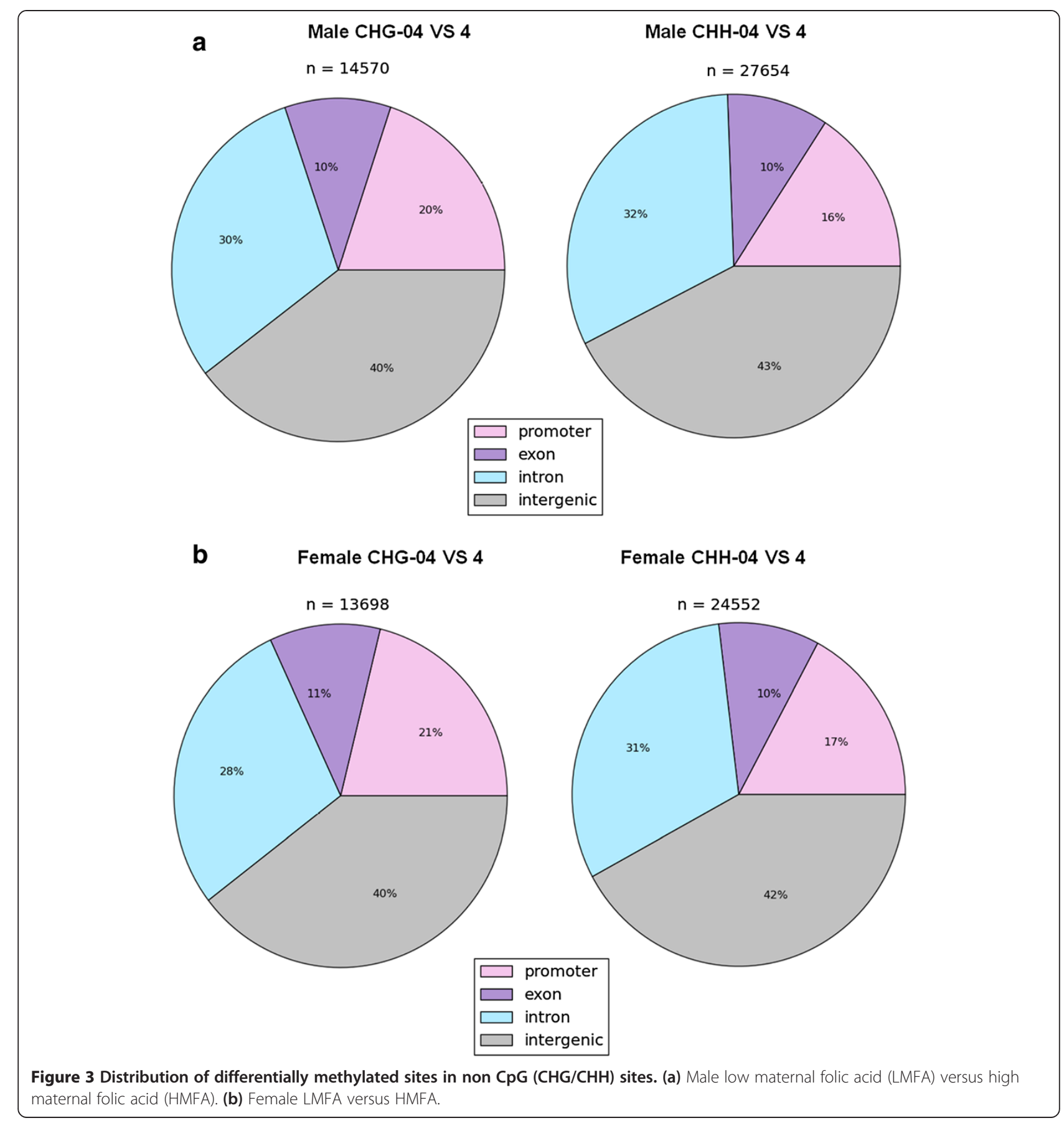

phenotypes. In addition, epigenetic modifications of the imprinted genes such as Dio3 can result in clinically significant phenotypes. It will be of interest to examine the impact of the dose and duration of maternal FA and the consequences of these epigenetic effects. Similar to hypermethylation, we observe hypomethylation in promoter regions of CpG sites in both male and female pups from HMFA in comparison with LMFA. The expression of Ror2 (hypomethylated in male pups) which plays a role during neurogenesis of the developing neocortex [27] was significantly downregulated in male pups, but no such changes were observed in female pups. Moreover, the expression of Mtap4 (hypomethylated in female pups) that has been shown to play a role in the central nervous system and regulation of the microtubule-dependent transport [28] was upregulated significantly in female pups from HMFA in comparison with LMFA, but the expression in male pups did not exhibit such significant changes. Intriguingly, the expression of Mrsps12 that exhibited hypomethylation in female pups from HMFA remained unchanged 
in comparison with LMFA. In contrast, the expression of Mrps12 in male pups was significantly downregulated in HMFA in comparison with LMFA, although no such changes in methylation pattern were observed. Of note, Mrps12 is a major component of the ribosomal accuracy center and has been shown to play a role in sensorineural deafness [29].

Recently, the methylation of non-CpG regions and its role in transcriptional repression have received greater attention $[30,31]$, and single-base resolution maps of the human genome have revealed a substantial presence of methylated cytosine residues in non-CpG contexts [32]. In this study, we found substantial differential methylation in non-CpG regions in gene promoters from newborns of HMFA and confirmed the variations in the expression of several genes. Notably, studies using the brain tissue from an Alzheimer disease model [33], fetal brain [34,35], adult tissues [36,37], and early embryo [38] have shown that methylation in both CpG islands and non-CpG regions correlates with the expression of several genes. Thus, variation of methylation in the non-CpG regions as a result of HMFA may modulate epigenetic-mediated transcriptional repression, although a direct causal connection cannot be established with our data. Further analysis of the methylation profile has shown substantial differential methylation in the gene body of the offspring DNA. This finding builds on growing evidence that maternal adversity during gestation induces unbiased epigenetic changes in offspring genome. Although aberrant methylation in gene promoter regions is known to be linked with altered gene expression, the effect of hypermethylation in the gene body is unclear and inconclusive [39]. Significant evidence indicates that gene body methylation is a general feature of highly expressed genes in human cell lines [40-42]. In contrast, a recent study in a mouse model has revealed that differential gene body methylation generally resulted in downregulation of gene expression [43]. We found both up- and downregulation in the expression of transcripts that exhibited hypermethylation in the gene body of the offspring from HMFA. Our study suggests that the relationship between gene body methylation and transcriptional level may be more complicated than previously thought and, perhaps, underappreciated. Intriguingly the mRNA expression of Shank3 was significantly downregulated in both male and female pups; in contrast, the expression of Auts 2 is downregulated in male pups but not in female pups. The genes Auts2 and Shank3 are associated with autism spectrum disorders and other neurological diseases $[44,45]$, and in this study both of the genes exhibited an alteration in methylation pattern in the gene body.

Our findings showed several distinct DMRs to be acting in a sexually dimorphic manner, similar to a recent study on imprinted genes in the placenta [46]. The relevance of epigenetic mechanisms in developing several complex diseases is sex-biased, and numerous studies have shown that during the developing windows of life the environmental factors, including nutrition during prenatal and postnatal life, influence epigenetic modulation in a sex-related manner [47-50]. Several studies in humans have further shown that various late-onset diseases are sex-biased and are highly related to maternal diet and body condition during pregnancy [51-53]. In this study, in the mouse model, we found that the expressions of several genes as a result of HMFA are highly biased in expression depending upon the gender. Furthermore, analysis of the methylation profile and gene expression between LMFA of male and female pups and between HMFA of male and female pups reveals striking sexual dimorphism. One possibility of such sexual dimorphism is the alterations in the uterine environment because of changes in FA level, and the methylation of imprinted genes may fine-tune selective events specific to one sex during developmental programming. Thus, the results of our study further highlight the relevance of studying both sexes in experimental models of maternal diet and may provide critical insight regarding the influence of FA in programming sex-biased methylation pattern.

It is paradoxical that the methylation profile of our findings shows a substantial hypomethylation to be present in the offspring DNA, even after supplementing HMFA. This finding indicates that the amount of gestational extracellular FA or cofactor required for the synthesis of Sadenosylmethionine probably can induce the site- and gene-specific nature of the methylation level in the offspring DNA, and probably the DNA methylation status is also dependent upon methylenetetrahydrofolate reductase (MTHFR) activity and not only on the folate status alone [54,55]. Moreover, because DNA methylation is a distinguishing feature that varies between cell types, specifically various neuronal populations, the variation in methylation (hypo/hyper) profile of our sample may be due to the cellular heterogeneity of the cerebral hemisphere [56-58].

\section{Methods}

\section{Mice strain and feeding}

Mice in this study were handled according to the protocol reviewed and approved by the Institute for Basic Research Institutional Animal Care and Use Committee. Adult, 8- to 10-week-old C57BL/6 J mice were used in all the experiments. Throughout the experimental procedure, controlled temperature and a fixed lighting schedule were maintained in the room. Given that most current commercial mice chow already contains quite high amounts of FA (2-3 mg/kg diet) and thus is unsuitable for the current studies, we developed a custom diet for this study. One week prior to mating, female mice were fed with a custom AIN-93G amino acid-based diet (Research Diet, Inc.), having FA at $0.4 \mathrm{mg} / \mathrm{kg}(\mathrm{n}=8-12)$, while the test group 
received FA at $4 \mathrm{mg} / \mathrm{kg}(\mathrm{n}=8-12)$. The diet was continued throughout the entire period of gestation.

\section{Tissue collection and DNA extraction}

At postnatal day 1 , six pups ( $n=6$, segregated by gender), all from different dams, in each diet group were sacrificed. Cerebral hemisphere tissues were pooled ( $\mathrm{n}=3$ /gender) for the $0.4 \mathrm{mg}$ group: three male pups (each from an independent dam) and three female pups (each from an independent dam), for a total of six pups $(n=6)$. Tissues from six pups ( $n=6$, segregated by gender) from the $4 \mathrm{mg}$ group were similarly processed. DNA was extracted from pooled cerebral hemispheres ( $n=3$ /gender per group) with the Epicentre MasterPure DNA purification kit (Epicentre Biotechnologies, Madison, WI, USA) in accordance with the protocol of the manufacturer. After re-suspension in TE buffer, the DNA concentration was measured by using NanoDrop ND-1000 (Thermo Scientific, Wilmington, DE, USA).

\section{Library construction}

To perform a genome-wide DNA methylation analysis, libraries were prepared from 200 to $500 \mathrm{ng}$ of genomic DNA digested sequentially with 60 units of TaqI and 30 units of MspI (New England Biolabs, Ipswich, MA, USA). The resulting size-selected TaqI-MspI fragments (40-120 bp and 120-350 bp) were filled in, and 3'terminal-A extended, extracted with DNA Clean \& Concentrator $^{\mathrm{Tm}}$ kit (Zymo Research, Irvine, CA, USA). Ligation of selected fragments to pre-annealed adapters containing 5 '-methyl-cytosine instead of cytosine was performed by using the Illumina DNA preparation kit in accordance with the protocol of the manufacturer (Illumina Inc., San Diego, CA, USA). Purified, adaptor-ligated fragments were then bisulphite-treated by using the EZ DNA Methylation-Direct $^{\mathrm{m}}$ Kit (Zymo Research). Preparativescale PCR was performed with the resulting fragments followed by purification of PCR products with DNA Clean \& Concentrator $^{\text {Tix }}$ (Zymo Research). Final size selection of the purified PCR products was performed by using $4 \%$ NuSieve 3:1 agarose gel. SYBR-green-stained gel slices of adapter-ligated fragments (130-210 bp or 210-460 bp in size) were excised, and library material was recovered by using the Zymoclean ${ }^{\mathrm{m}}$ Gel DNA Recovery Kit (Zymo Research). Sequencing was performed on an Illumina HiSeq genome analyzer.

\section{Sequence alignments and data analysis}

Using standard base-calling software, sequence reads from bisulfite-treated EpiQuest libraries were identified. Further analysis was performed by using a Zymo Research proprietary analysis pipeline. First, residual cytosines (Cs) in each read were converted to thymines (Ts), with each conversion noted for subsequent analysis. From the 50-bp ends of each computationally predicted MspITaqI fragment (40- to 350-bp size range), a reference sequence database was constructed. All Cs in each fragment end were then converted to Ts; only the C-poor strands are sequenced in the RRBS (reduced representation bisulfite sequencing) process. Then, using Bowtie software (http://bowtie-bio.sourceforge.net/index.shtml), the converted reads were aligned to the converted reference. The number of mismatches in the induced alignment was then counted between the unconverted read and reference, ignoring cases in which a $\mathrm{T}$ in the unconverted read was matched to a $\mathrm{C}$ in the unconverted reference. For a given read, the best alignment was kept if the second-best alignment had two more mismatches; otherwise, the read was discarded as non-unique. The methylation level of each sampled $C$ was estimated as the number of reads reporting a $\mathrm{C}$, divided by the total number of reads reporting a $\mathrm{C}$ or T. For each CpG site, Fisher's exact test or $t$ test was performed, which covered at least five reads. Also, promoter, gene body, and CpG island annotations were added for each CpG. The software pipeline is implemented in Python. All the procedures above were carried out in the Zymo Epigentic Core Services (Zymo Research).

\section{RNA preparation and quantitative real time reverse transcription-polymerase chain reaction analysis}

At postnatal day 1 , six pups ( $\mathrm{n}=6$, segregated by gender) from different dams in each diet group were sacrificed. Cerebral hemisphere tissues were pooled $(n=3 /$ gender) for the $0.4 \mathrm{mg}$ group: three male pups (each from an independent dam) and three female pups (each from an independent dam), for a total of six pups $(n=6)$. Tissues from six pups $(n=6)$ from the $4 \mathrm{mg}$ group were similarly processed. Considering the degree of inter-variability, RNA extractions were repeated from a different batch (pooled samples, $\mathrm{n}=3$ for each group/gender, with each mouse from a different dam). Total RNA was extracted by lysing the cells with Trizol reagent (Invitrogen Life Technologies, Inc., Carlsbad, CA, USA). Further purification of RNA was carried out using RNeasy kit (Qiagen, Valencia, CA, USA) in accordance with the instructions of the manufacturer. On-column DNase digestion for each sample was performed to remove any DNA contamination. The quality of RNA was assessed by measuring the absorbance ratio at $260 / 280 \mathrm{~nm}$ by using NanoDrop ND1000 (Thermo Scientific). The integrity of RNA was further assessed by formaldehyde-gel electrophoresis. Quantitative real time reverse transcription-polymerase chain reaction amplifications were performed with either One-Step iScript kit (Bio-Rad, Hercules, CA, USA) or Two-step kit in which the first-strand cDNA from each sample was synthesized from $1 \mu \mathrm{g}$ total RNA by using the First-Strand cDNA Synthesis kit (Affymetrix, Santa Clara, CA, USA) in accordance with the protocol of the manufacturer. qRT-PCR was 
performed by using the Mastercycler ep Realplex system (Eppendorf AG, Hamburg, Germany) in combination with the $\mathrm{RT}^{2}$ SYBRGreen PCR Master Mix (Qiagen). Each reaction was run in duplicate and repeated at least two times each from different batches of RNA (pooled $n=3$ per batch/gender). Hprt1 was used as endogenous control for amplification. Relative gene expression was calculated by using the Pfaffl method [59]. Primers used for qRT-PCR are listed in Additional file 24: Table S12. Statistical analysis was done by using Prism Software (GraphPad, San Diego, CA, USA). Values are presented as means \pm standard deviation, and numerical results are presented considering $P<0.05$ as significant.

\section{Conclusions}

In summary, we have identified substantial DMRs in the cerebral hemispheres of the offspring, revealing that the HMFA diet causes epigenetic modifications. A key finding of this study is the presence of DMRs in non-CpG regions, along with $\mathrm{CpG}$ sites at single-base resolution, as a result of HMFA. Because numerous studies have shown that abnormalities in the frontal lobes impact brain development and autism [60,61], our study's findings could provide a completely novel insight into the etiology of complex developmental disorders and foster the development of corrective strategies. However, we do not rule out the limitation of our study that the methylation and gene expression do not necessarily indicate change in function, and thus further studies are required in a larger number of samples to verify the functional outcome and phenotypes.

\section{Additional files}

Additional file 1: Table S1. Descriptive statistics of the mapping of methylation profile of the cerebral hemispheres of offspring from low maternal folic acid (LMFA) and high maternal folic acid (HMFA) diets.

Additional file 2: Table S2. Genes in male offspring from high maternal folic acid (HMFA) diet, which were enriched with methylation in the gene body and other chromosomal regions in $\mathrm{CpG} / \mathrm{CHG} / \mathrm{CHH}$ contexts.

Additional file 3: Table S3. Genes in female offspring from high maternal folic acid (HMFA), which were enriched with methylation in the gene body and other chromosomal region in $\mathrm{CpG} / \mathrm{CHG} / \mathrm{CHH}$ contexts.

Additional file 4: Table S5. Genes that were hypomethylated in the $\mathrm{CpG} / \mathrm{CHG} / \mathrm{CHH}$ contexts of the male offspring from high maternal folic acid (HMFA) diet.

Additional file 5: Table S6. Genes that were hypomethylated in the $\mathrm{CpG} / \mathrm{CHG} / \mathrm{CHH}$ region of the female offspring from high maternal folic acid (HMFA) diet.

Additional file 6: Figures S1-S6. Scatter plot representing the distribution of the methylation ratio for corresponding sites of low maternal folic acid (LMFA) versus high maternal folic acid (HMFA). Pearson's correlation coefficient is denoted in the center of each scatter plot

Additional file 7: Figures S7-S9. Hexbin plot representing the overlapped sites in CpG $(n=4,378)$, CHG $(n=71)$, and CHH $(n=149)$ regions between male and female pups from high maternal folic acid (HMFA) in comparison with low maternal folic acid (LMFA) from total significant $(P<0.05)$ differential methylation sites. Each dot in hexbin plot is one of the overlapped sites. The colors blue, green, yellow and red represent the dot density from lower to higher order in accordance with the prevalence of the overlapping sites.

Additional file 8: Figures S10, S11. Box plot illustrating the methylation levels across non-CpG islands of the cerebral hemispheres from male pups (S10) having low maternal folic acid (LMFA) ( $n=36,319$ and median $=0.65)$ and high maternal folic acid (HMFA) $(n=36,319$ and median $=0.73)$ and from female pups (S11) having LMFA ( $n=48,438$ and median $=0.66)$ and HMFA $(n=48,438$ and median $=0.69)$ as assessed by reduced representation bisulfite sequencing (RRBS). Boxes are 25th and 75th quartiles; horizontal yellow bar in the middle represents the median DNA methylation value. Whisker indicates the 5 th and 95th percentiles.

Additional file 9: Table S4. Genes in male and female offspring from high maternal folic acid (HMFA), which were enriched with methylation in the gene promoters in $\mathrm{CHG} / \mathrm{CHH}$.

Additional file 10: Figure S12. A representative figure of the data uploaded in the University of California at Santa Cruz (UCSC) Genome Browser. Comparison of DNA methylation patterns in the offspring's cerebral hemisphere from low maternal folic acid (LMFA) and high maternal folic acid (HMFA). Example of the S/c5a1 gene in chromosome 5 that was differentially methylated in the CHG contexts of promoter region of male offspring. Yellow color bars indicate gain of methylation.

Additional file 11: Figures S13, S14. Box plot illustrating the methylation levels across exons of the cerebral hemispheres from male pups (S13) having low maternal folic acid (LMFA) $(n=8,136$ and median $=0.42)$ and high maternal folic acid (HMFA) $(n=8,136$ and median $=0.5)$ and from female pups (S14) having LMFA ( $n=10,335$ and median $=0.44)$ and HMFA ( $n=10,335$ and median $=0.5$ ) as assessed by reduced representation bisulfite sequencing (RRBS). Boxes are 25th and 75th quartiles; horizontal yellow bar in the middle represents the median DNA methylation value. Whisker indicates the 5th and 95th percentiles.

Additional file 12: Figure S15. Distribution of differentially methylated sites in CpG island sequences between males and females from (a) low maternal folic acid (LMFA) and (b) high maternal folic acid (HMFA).

Additional file 13: Figure S16. Distribution of differentially methylated sites in non CpG island sequences between males and females from (a) low maternal folic acid (LMFA) and (b) high maternal folic acid (HMFA).

Additional file 14: Table S7. Genes in female offspring from low maternal folic acid (LMFA) diet, which were enriched with methylation, compared with male offspring in the $\mathrm{CpG} / \mathrm{CHG} / \mathrm{CHH}$ contexts.

Additional file 15: Table S8. Genes in female offspring from low maternal folic acid (LMFA) diet, which were hypomethylated, compared with male offspring in the $\mathrm{CpG} / \mathrm{CHG} / \mathrm{CHH}$ contexts.

Additional file 16: Table S9. Genes in female offspring from high maternal folic acid (HMFA) diet, which were enriched with methylation, compared with male offspring in the $\mathrm{CpG} / \mathrm{CHG} / \mathrm{CHH}$ contexts.

Additional file 17: Table S10. Genes in female offspring from high maternal folic acid (HMFA) diet, which were hypomethylated, compared with male offspring in the promoter region in $\mathrm{CpG} / \mathrm{CHG} / \mathrm{CHH}$ contexts.

Additional file 18: Figures $\mathbf{S 1 7}(\mathbf{a}, \mathbf{b}, \mathbf{c})$. Scatter plot representing the distribution of the methylation ratio for corresponding sites of low maternal folic acid (LMFA) male versus LMFA female in $\mathrm{CpG} / \mathrm{CHG} / \mathrm{CHH}$ regions. Pearson's correlation coefficient is denoted in the center of each scatter plot.

Additional file 19: Figures $\mathbf{S 1 8}(\mathbf{a}, \mathbf{b}, \mathbf{c})$. Scatter plot representing the distribution of the methylation ratio for corresponding sites of high maternal folic acid (HMFA) male versus HMFA female in $\mathrm{CpG} / \mathrm{CHG} / \mathrm{CHH}$ regions. Pearson's correlation coefficient is denoted in the center of each scatter plot.

Additional file 20: Figures $\mathbf{S 1 9}(\mathbf{a}, \mathbf{b}, \mathbf{c})$. Hexbin plot representing the overlapped sites in CpG $(n=6,085), \mathrm{CHG}(n=96)$, and CHH $(n=154)$ regions between male and female pups from LMFA compared with high maternal folic acid (HMFA) pups from total significant $(P<0.05)$ differential methylation sites. Each dot in hexbin plot is one of the overlapped sites. The colors blue, green, yellow, and red represent the dot density from lower to higher order in accordance to the prevalence of the overlapping sites. 
Additional file 21: Figure S20a. Quantitative real time reverse transcription-polymerase chain reaction ( $\mathrm{R} R T-P C R$ ) showing relative expression of the transcripts of genes in female pups that exhibited hypermethylation or hypomethyaltion in the cerebral hemispheres in comparison with male pups from low maternal folic acid (LMFA). The results were normalized to Hprt transcript expression and were expressed as relative values in comparison with corresponding transcripts from male LMFA. Results represent mean \pm standard deviation (SD); asterisks denote statistically significant change $\left({ }^{*} P<0.05,{ }^{* *} P<0.01,{ }^{* * *} P<0.001\right)$. Figure S20b. qRT-PCR showing relative expression of the transcripts of genes in female pups that exhibited hypermethylation or hypomethyaltion in the cerebral hemispheres in comparison with male pups from high maternal folic acid (HMFA). The results were normalized to Hprt transcript expression and were expressed as relative values in comparison with corresponding transcripts from male HMFA. Results represent mean $\pm \mathrm{SD}$; asterisks denote statistically significant change ( ${ }^{*} P<0.05$, ${ }^{*} P<0.01$, ${ }^{* *} P<0.001$ ).

Additional file 22: Figure S21a. Quantitative real time reverse transcription-polymerase chain reaction ( $q R T-P C R)$ showing relative expression of the transcripts of genes in male pups from high maternal folic acid (HMFA) that exhibited no alterations in the methylation profile in promoter and gene body in the cerebral hemispheres compared with low maternal folic acid (LMFA). The results were normalized to Hprt transcript expression and were expressed as relative values in comparison with corresponding transcripts from LMFA. Results represent mean \pm standard deviation (SD); asterisks denote statistically significant change ${ }^{*} P<0.05$, $\left.{ }^{*} P<0.01,{ }^{* *} P<0.001\right)$. Figure $\mathbf{S} 21$ b. $q R T-P C R$ showing relative expression of the transcripts of genes in female pups from HMFA that exhibited no alterations in the methylation profile in promoter and gene body in the cerebral hemispheres compared with LMFA. The results were normalized to Hprt transcript expression and were expressed as relative values in comparison with corresponding transcripts from LMFA. Results represent mean $\pm \mathrm{SD}$; asterisks denote statistically significant change $\left({ }^{*} P<0.05, * * P<0.01, * * * P<0.001\right)$.

Additional file 23: Table S11. List of top 100 sites, sorted by $P$ value, which exhibited cis-alterations in male and female offspring in the CpG/ CHG contexts.

Additional file 24: Table S12. List of primers used for quantitative real time reverse transcription-polymerase chain reaction (qRT-PCR) in this study.

\section{Abbreviations}

C: cytosine; DMR: differentially methylated region; FA: folic acid; HMFA: high maternal folic acid; LMFA: low maternal folic acid; NTD: neural tube defect; qRT-PCR: quantitative real time reverse transcription-polymerase chain reaction; T: thymine.

\section{Competing interests}

The authors declare that they have no competing interests.

\section{Authors' contributions}

SB helped to perform the experiments, to analyze the data, and to write the paper. SK and KKC helped to perform the experiments. MAJ helped to perform the experiments, to analyze the data, to write the paper, and to conceptualize the research. MJF helped to analyze the data. WTB helped to analyze the data and to conceptualize the research. All authors read and approved the final manuscript.

\section{Acknowledgments}

Financial support from the March of Dimes Research Foundation (12-FY12-170) and the New York State Office for People With Developmental Disabilities is gratefully acknowledged. We acknowledge Maureen Marlow for help with editorial corrections with the manuscript.

\section{Author details}

'Department of Developmental Biochemistry, New York State Institute for Basic Research in Developmental Disabilities, 1050 Forest Hill Road, Staten Island, NY 10314, USA. ²Department of Developmental Neurobiology, New York State Institute for Basic Research in Developmental Disabilities, 1050 Forest Hill Road, Staten Island, NY 10314, USA. ${ }^{3}$ Department of Infant Development, New York State Institute for Basic Research in Developmental
Disabilities, 1050 Forest Hill Road, Staten Island, NY 10314, USA. ${ }^{4}$ Department of Human Genetics, New York State Institute for Basic Research in Developmental Disabilities, 1050 Forest Hill Road, Staten Island, NY 10314, USA. ${ }^{5}$ Structural Neurobiology Laboratory, Department of Developmental Biochemistry, New York State Institute for Basic Research in Developmental Disabilities, 1050 Forest Hill Road, Staten Island, NY 10314, USA.

Received: 21 August 2013 Accepted: 7 January 2014

Published: 3 February 2014

\section{References}

1. Bailey LB, Gregory JF III: Folate metabolism and requirements. J Nutr 1999, 129:779-782.

2. Friso S, Choi SW: Gene-nutrient interactions in one-carbon metabolism. Curr Drug Metab 2005, 6:37-46.

3. Chanarin I, Macgibbon BM, O'Sullivan WJ, Mollin DL: Folic-acid deficiency in pregnancy, The pathogenesis of megaloblastic anaemia of pregnancy. Lancet 1959, 2:634-639.

4. Hibbard BM, Hibbard ED, Jeffcoate TN: Folic acid and reproduction. Acta Obstet Gynecol Scand 1965, 44:375-400.

5. Smithells RW, Sheppard S, Schorah CJ: Vitamin deficiencies and neural tube defects. Arch Dis Child 1976, 51:944-950.

6. U.S. Preventive Services Task Force: Folic acid for the prevention of neural tube defects: U.S. Preventive Services Task Force recommendation statement. Ann Intern Med 2009, 150:626-631.

7. Haberg SE, London SJ, Stigum H, Nafstad P, Nystad W: Folic acid supplements in pregnancy and early childhood respiratory health. Arch Dis Child 2009, 94:180-184.

8. Whitrow MJ, Moore VM, Rumbold AR, Davies MJ: Effect of supplemental folic acid in pregnancy on childhood asthma: a prospective birth cohort study. Am J Epidemiol 2009, 170:1486-1493.

9. Steegers-Theunissen RP, Obermann-Borst SA, Kremer D, Lindemans J, Siebel C, Steegers EA, Slagboom PE, Heijmans BT: Periconceptional maternal folic acid use of 400 microg per day is related to increased methylation of the IGF2 gene in the very young child. PLoS One 2009, 4:e7845.

10. Junaid MA, Kuizon S, Cardona J, Azher T, Murakami N, Pullarkat RK, Brown WT: Folic acid supplementation dysregulates gene expression in lymphoblastoid cells-implications in nutrition. Biochem Biophys Res Commun 2011, 412:688-692

11. Heid MK, Bills ND, Hinrichs SH, Clifford AJ: Folate deficiency alone does not produce neural tube defects in mice. J Nutr 1992, 122:888-894.

12. Docherty SJ, Davis OS, Haworth CM, Plomin R, Mill J: Bisulfite-based epityping on pooled genomic DNA provides an accurate estimate of average group DNA methylation. Epigenetics Chromatin 2009, 2:3.

13. Docherty SJ, Davis OS, Haworth CM, Plomin R, Mill J: DNA methylation profiling using bisulfite-based epityping of pooled genomic DNA Methods 2010, 52:255-258.

14. Brooks AJ, Waters MJ: The growth hormone receptor: mechanism of activation and clinical implications. Nat Rev Endocrinol 2010, 6:515-525.

15. Banerjee-Basu S, Packer A: SFARI Gene: an evolving database for the autism research community. Dis Model Mech 2010, 3:133-135.

16. Abrahams BS, Geschwind DH: Advances in autism genetics: on the threshold of a new neurobiology. Nat Rev Genet 2008, 9:341-355.

17. Glessner JT, Wang K, Cai G, Korvatska O, Kim CE, Wood S, Zhang H, Estes A, Brune CW, Bradfield JP, Imielinski M, Frackelton EC, Reichert J, Crawford EL, Munson J, Sleiman PM, Chiavacci R, Annaiah K, Thomas K, Hou C, Glaberson W, Flory J, Otieno F, Garris M, Soonya L, Klei L, Piven J, Meyer KJ, Anagnostou E, Sakurai T, et al: Autism genome-wide copy number variation reveals ubiquitin and neuronal genes. Nature 2009, 459:569-573.

18. Gupta AR, State MW: Recent advances in the genetics of autism. Biol Psychiatry 2007, 61:429-437.

19. Gillberg C, Wahlstrom J, Johansson R, Tornblom M, Albertsson-Wikland K Folic acid as an adjunct in the treatment of children with the autism fragile-X syndrome (AFRAX). Dev Med Child Neurol 1986, 28:624-627.

20. Suren P, Roth C, Bresnahan M, Haugen M, Hornig M, Hirtz D, Lie KK, Lipkin WI, Magnus P, Reichborn-Kjennerud T, Schjolberg S, Davey SG, Oyen AS, Susser E, Stoltenberg C: Association between maternal use of folic acid supplements and risk of autism spectrum disorders in children. JAMA 2013, 309:570-577.

21. Tamura T, Picciano MF: Folate and human reproduction. Am J Clin Nutr 2006, 83:993-1016. 
22. Stubbs G, Litt M, Lis E, Jackson R, Voth W, Lindberg A, Litt R: Adenosine deaminase activity decreased in autism. J Am Acad Child Psychiatry 1982, $21: 71-74$

23. Bottini $N$, De Luca D, Saccucci $P$, Fiumara A, Elia M, Porfirio MC, Lucarelli $P$, Curatolo P: Autism: evidence of association with adenosine deaminase genetic polymorphism. Neurogenetics 2001, 3:111-113.

24. Hettinger JA, Liu X, Holden JJ: The G22A polymorphism of the ADA gene and susceptibility to autism spectrum disorders. J Autism Dev Disord 2008, 38:14-19.

25. Ozsahin H, Arredondo-Vega FX, Santisteban I, Fuhrer H, Tuchschmid P, Jochum W, Aguzzi A, Lederman HM, Fleischman A, Winkelstein JA, Seger RA, Hershfield MS: Adenosine deaminase deficiency in adults. Blood 1997, 89:2849-2855.

26. Hirschhorn R: Adenosine deaminase deficiency. Immunodefic Rev 1990, 2:175-198.

27. Endo M, Doi R, Nishita M, Minami Y: Ror family receptor tyrosine kinases regulate the maintenance of neural progenitor cells in the developing neocortex. J Cell Sci 2012, 125:2017-2029.

28. Tokuraku K, Okuyama S, Matsushima K, Ikezu T, Kotani S: Distinct neuronal localization of microtubule-associated protein 4 in the mammalian brain. Neurosci Lett 2010, 484:143-147.

29. Shah ZH, O'Dell KM, Miller SC, An X, Jacobs HT: Metazoan nuclear genes for mitoribosomal protein S12. Gene 1997, 204:55-62.

30. Dyachenko OV, Schevchuk TV, Kretzner L, Buryanov YI, Smith SS: Human non-CG methylation: are human stem cells plant-like? Epigenetics 2010, 5:569-572.

31. Yan J, Zierath JR, Barres R: Evidence for non-CpG methylation in mammals. Exp Cell Res 2011, 317:2555-2561.

32. Lister R, Pelizzola M, Dowen RH, Hawkins RD, Hon G, Tonti-Filippini J, Nery JR, Lee L, Ye Z, Ngo QM, Edsall L, Antosiewicz-Bourget J, Stewart R, Ruotti V, Millar AH, Thomson JA, Ren B, Ecker JR: Human DNA methylomes at base resolution show widespread epigenomic differences. Nature 2009, 462:315-322

33. Fuso A, Nicolia V, Pasqualato A, Fiorenza MT, Cavallaro RA, Scarpa S: Changes in Presenilin 1 gene methylation pattern in diet-induced $B$ vitamin deficiency. Neurobiol Aging 2011, 32:187-199.

34. Inoue S, Oishi M: Effects of methylation of non-CpG sequence in the promoter region on the expression of human synaptotagmin XI (syt11) Gene 2005, 348:123-134.

35. Vu TH, Li T, Nguyen D, Nguyen BT, Yao XM, Hu JF, Hoffman AR: Symmetric and asymmetric DNA methylation in the human IGF2-H19 imprinted region. Genomics 2000, 64:132-143.

36. Malone CS, Miner MD, Doerr JR, Jackson JP, Jacobsen SE, Wall R, Teitell M: $\mathrm{CmC}(\mathrm{A} / \mathrm{T}) \mathrm{GG}$ DNA methylation in mature $B$ cell lymphoma gene silencing. Proc Natl Acad Sci U S A 2001, 98:10404-10409.

37. Teng C, Gladwell W, Raphiou I, Liu E: Methylation and expression of the lactoferrin gene in human tissues and cancer cells. Biometals 2004, $17: 317-323$

38. Haines TR, Rodenhiser DI, Ainsworth PJ: Allele-specific non-CpG methylation of the Nf1 gene during early mouse development. Dev Biol 2001, 240:585-598

39. Suzuki MM, Bird A: DNA methylation landscapes: provocative insights from epigenomics. Nat Rev Genet 2008, 9:465-476.

40. Ball MP, Li JB, Gao Y, Lee JH, LeProust EM, Park IH, Xie B, Daley GQ, Church GM: Targeted and genome-scale strategies reveal gene-body methylation signatures in human cells. Nat Biotechnol 2009, 27:361-368.

41. Hellman A, Chess A: Gene body-specific methylation on the active $X$ chromosome. Science 2007, 315:1141-1143.

42. Rauch TA, Wu X, Zhong X, Riggs AD, Pfeifer GP: A human B cell methylome at 100-base pair resolution. Proc Natl Acad Sci USA 2009, 106:671-678.

43. Oh JE, Chambwe N, Klein S, Gal J, Andrews S, Gleason G, Shaknovich R, Melnick A, Campagne F, Toth M: Differential gene body methylation and reduced expression of cell adhesion and neurotransmitter receptor genes in adverse maternal environment. Trans/ Psychiatry 2013, 3:e218.

44. Moessner R, Marshall CR, Sutcliffe JS, Skaug J, Pinto D, Vincent J, Zwaigenbaum L, Fernandez B, Roberts W, Szatmari P, Scherer SW: Contribution of SHANK3 mutations to autism spectrum disorder. Am J Hum Genet 2007, 81:1289-1297.

45. Oksenberg N, Ahituv N: The role of AUTS2 in neurodevelopment and human evolution. Trends Genet 2013, 29:600-608.
46. Gallou-Kabani C, Gabory A, Tost J, Karimi M, Mayeur S, Lesage J, Boudadi E, Gross MS, Taurelle J, Vige A, Breton C, Reusens B, Remacle C, Vieau D, Ekstrom TJ, Jais JP, Junien C: Sex- and diet-specific changes of imprinted gene expression and DNA methylation in mouse placenta under a high-fat diet. PLoS One 2010, 5:e14398.

47. Gabory A, Attig L, Junien C: Developmental programming and epigenetics. Am J Clin Nutr 2011, 94:1943S-1952S.

48. Gabory A, Attig L, Junien C: Sexual dimorphism in environmental epigenetic programming. Mol Cell Endocrinol 2009, 304:8-18.

49. Flanagan DE, Moore VM, Godsland IF, Cockington RA, Robinson JS, Phillips DI: Fetal growth and the physiological control of glucose tolerance in adults: a minimal model analysis. Am J Physiol Endocrinol Metab 2000, 278:E700-E706.

50. Sugden MC, Holness MJ: Gender-specific programming of insulin secretion and action. J Endocrinol 2002, 175:757-767.

51. Ozaki T, Nishina $H$, Hanson MA, Poston L: Dietary restriction in pregnant rats causes gender-related hypertension and vascular dysfunction in offspring. J Physiol 2001, 530:141-152

52. Kwong WY, Wild AE, Roberts P, Willis AC, Fleming TP: Maternal undernutrition during the preimplantation period of rat development causes blastocyst abnormalities and programming of postnatal hypertension. Development 2000, 127:4195-4202.

53. Woods LL, Weeks DA, Rasch R: Programming of adult blood pressure by maternal protein restriction: role of nephrogenesis. Kidney Int 2004, 65:1339-1348

54. Friso S, Choi SW, Girelli D, Mason JB, Dolnikowski GG, Bagley PJ, Olivieri O, Jacques PF, Rosenberg $\mathrm{H}$, Corrocher R, Selhub J: A common mutation in the 5,10-methylenetetrahydrofolate reductase gene affects genomic DNA methylation through an interaction with folate status. Proc Natl Acad Sci USA 2002, 99:5606-5611.

55. Chen Z, Schwahn BC, Wu Q, He X, Rozen R: Postnatal cerebellar defects in mice deficient in methylenetetrahydrofolate reductase. Int J Dev Neurosci 2005, 23:465-474.

56. Guintivano J, Aryee MJ, Kaminsky ZA: A cell epigenotype specific model for the correction of brain cellular heterogeneity bias and its application to age, brain region and major depression. Epigenetics 2013, 8:290-302.

57. Iwamoto K, Bundo M, Ueda J, Oldham MC, Ukai W, Hashimoto E, Saito T, Geschwind DH, Kato T: Neurons show distinctive DNA methylation profile and higher interindividual variations compared with non-neurons. Genome Res 2011, 21:688-696.

58. Ohgane J, Yagi S, Shiota K: Epigenetics: the DNA methylation profile of tissue-dependent and differentially methylated regions in cells. Placenta 2008, 29(Suppl A):S29-S35.

59. Tichopad A, Dilger M, Schwarz G, Pfaffl MW: Standardized determination of real-time PCR efficiency from a single reaction set-up. Nucleic Acids Res 2003, 31:e122

60. Amaral DG, Schumann CM, Nordahl CW: Neuroanatomy of autism. Trends Neurosci 2008, 31:137-145.

61. Courchesne $E$, Pierce $K$ : Why the frontal cortex in autism might be talking only to itself: local over-connectivity but long-distance disconnection. Curr Opin Neurobiol 2005, 15:225-230.

doi:10.1186/1756-8935-7-3

Cite this article as: Barua et al:: Single-base resolution of mouse offspring brain methylome reveals epigenome modifications caused by gestational folic acid. Epigenetics \& Chromatin 2014 7:3.

\section{Submit your next manuscript to BioMed Central and take full advantage of:}

- Convenient online submission

- Thorough peer review

- No space constraints or color figure charges

- Immediate publication on acceptance

- Inclusion in PubMed, CAS, Scopus and Google Scholar

- Research which is freely available for redistribution 